\title{
Electroretinogram and visual evoked response in a form of ' neuronal lipidosis' with diagnostic EEG features
}

\author{
ANN HARDEN, G. PAMPIGLIONE, AND N. PICTON-ROBINSON \\ From the Department of Neurophysiology, The Hospital for Sick Children, \\ Great Ormond Street, London
}

SUMMARY Combined recordings of the electroretinogram (ERG) and the cortical visual evoked response (VER) have been made together with the electroencephalogram (EEG) in 16 children suffering from a 'late infantile' form of 'neuronal lipidosis'. The ERG was not usually recordable, in keeping with a gross loss of function of the retinal receptor elements. However, in all the 16 children, at whatever stage of the disease, a grossly enlarged VER was seen (some 12 to 20 times higher in amplitude than in a control group) and visible as a discharge on the primary EEG tracing. The first components of the VER were, however, of fairly similar wave form and latency to those seen in the control children. This unusual combination of ERG and VER findings together with the EEG features have not been found in other groups of diseases.

Among the rare neurometabolic disorders known as 'neuronal lipidoses' there is a group of patients who show certain electroencephalographic (EEG) features not seen in any other group of disorders (Pampiglione, 1961, 1968; Pampiglione and Lehovsky, 1968). A distinctive feature during photic stimulation is the appearance in the EEG of large polyphasic spikes mainly over the posterior regions of the head in response to low rates of flash. The EEG is considered to have diagnostic importance in separating this particular group of patients from a wider range of cases often referred to as 'Batten's disease' (Pampiglione and Harden, 1973).

As the visual system is involved in many familial degenerative disorders, and because a photic stimulus elicits unusual discharges in these patients, a special study has now been made of both the electroretinogram (ERG) and the summated visual evoked responses from the cortex (VER) together with the EEG.

\section{METHOD}

Since 1968,16 children suffering from this particular form of 'neuronal lipidosis' were diagnosed from rectal or cerebral biopsy as 'Batten's disease' (except for one sibling) and all showed a very similar clinical course-onset of fits beginning between 2 and 4 years, a characteristic progressive motor and later mental deterioration, increasing myoclonic phenomena, and death usually before the age of 9 years. These children were part of a larger group seen since 1959 all with the same disorder (Pampiglione and Harden, 1973). The 16 children (nine girls and seven boys) were aged between 3 and 7 years at the time of these ERG and VER studies. In addition, a control group of 28 children without known visual or cerebral disorders and also aged between 3 and 7 years had similar neurophysiological studies for comparison.

The EEGs were taken with a technique already described (Pampiglione and Harden, 1973). The electrodes were silver/silver chloride discs arranged on the scalp according to measurements from bony landmarks (Pampiglione, 1956) and fixed with collodion. In addition to the electrodes routinely placed for EEG (which included a midline occipital electrode $2 \mathrm{~cm}$ above the inion and one at the vertex), an electrode was also placed on the bridge of the nose at the level of the eyes for the recording of the ERG. Often another similar electrode was placed on the cheek and/or an ear-lobe as a reference point in addition to the vertex. Contact of all electrodes to 
Age 6yrs.

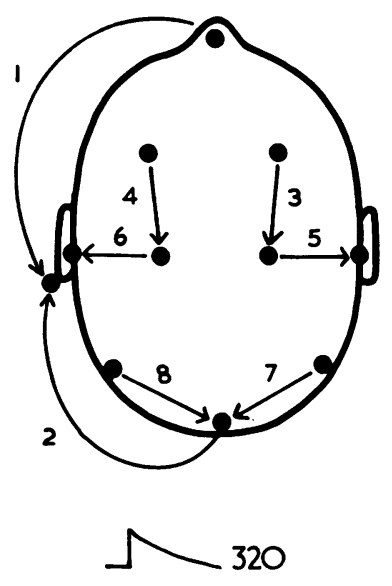

Light flash

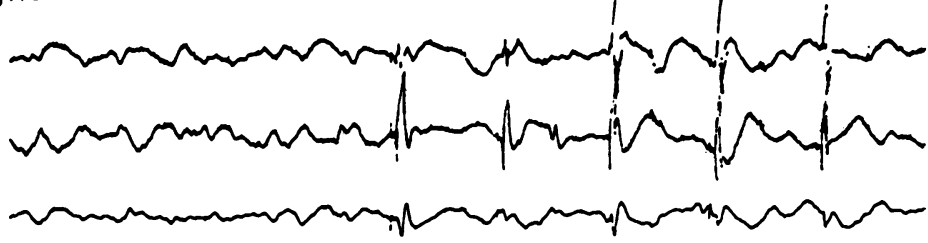

1

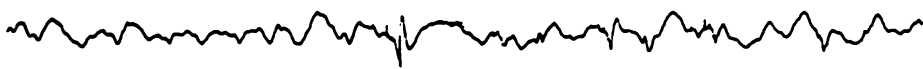

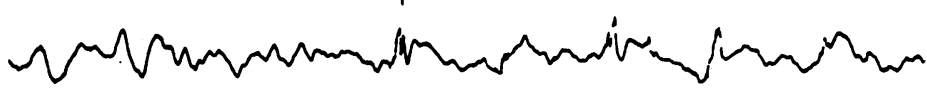

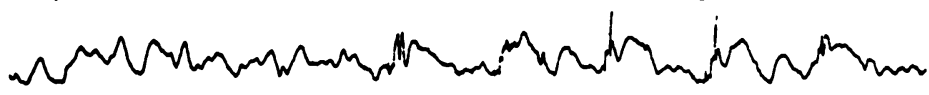

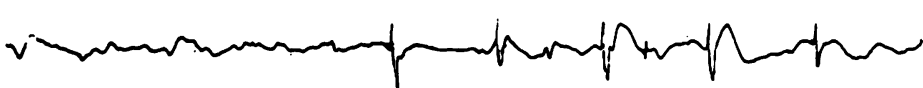
1sec.

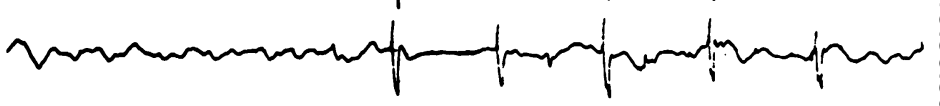

Light flash
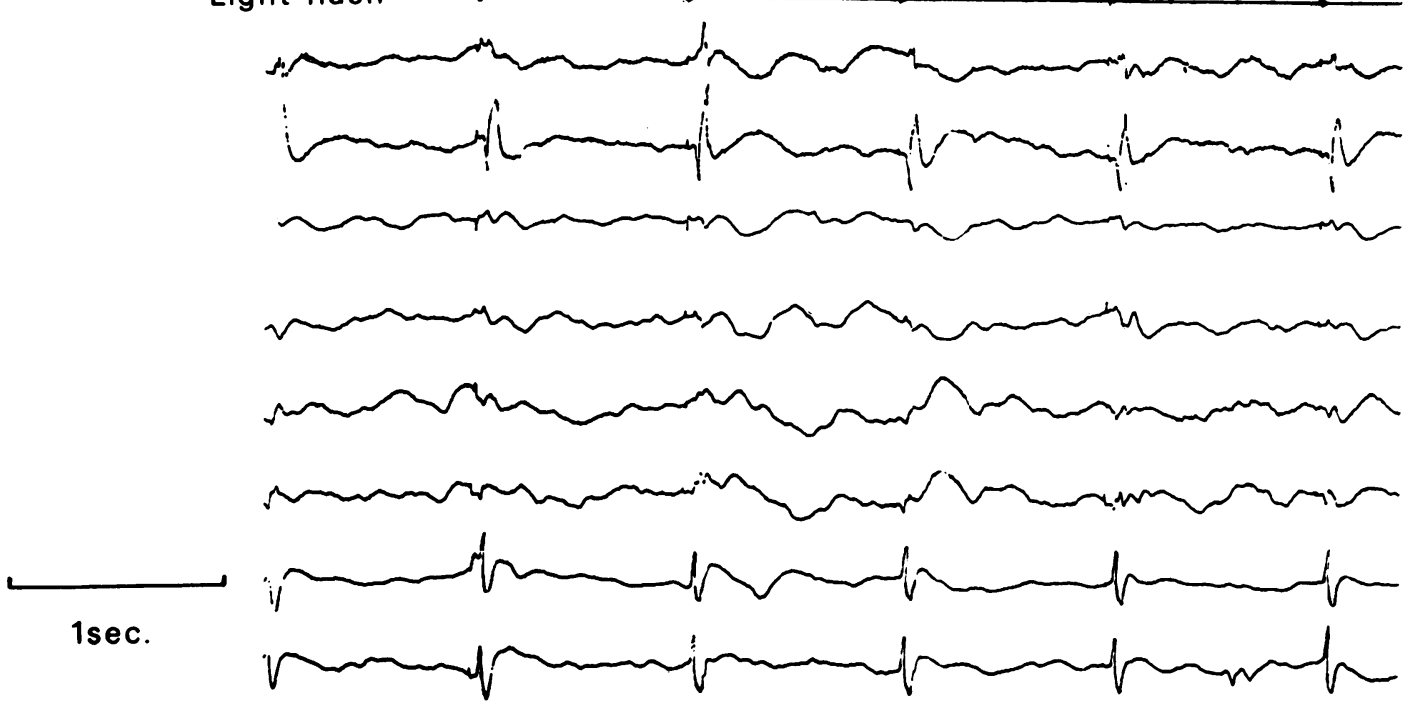

FIG. 1. Note discharges in EEG in relation to each flash of light (calibration signal $320 \mu V$ ). The VER is recorded from channel 2 (mid occipital region referred to the left earlobe) and the waveform of each discharge (best seen at the faster paper speed on bottom tracing) is similar to the summated response seen in Fig. 2. 
the skin was made by a saline jelly and the resistance was lowered to $5-10 \mathrm{k} \Omega$. The paper speed of the EEG recording during photic stimulation was $3 \mathrm{~cm}$ or $6 \mathrm{~cm} / \mathrm{sec}$. The ERG and VER were recorded together with the EEG according to a technique previously described (Harden and Pampiglione, 1970). The patients were mostly in the waking state with the eyes open, no sedatives or mydriatics having been given for this test. A total of 38 combined EEG, ERG, and VER recordings were taken on these 16 patients, being repeated in a number of children over a period of up to two and a half years.

Visual stimuli were presented to the patient from a gas-discharge lamp held manually, so that movements of the patient's head could be followed, at a distance of about 10 to $15 \mathrm{~cm}$ from the eyes. Flashes of light were presented at the rate of $2 / \mathrm{sec}$ and often also at $1 / \mathrm{sec}$. The number of stimuli for each summated response was programmed according to the size of the response but usually ranging between 25 and 100 flashes. A permanent record of the summated analogue signals was made at the end of each series of stimuli with an XY plotter. The whole equipment was mounted on a trolley so that it could be taken to the patient's bedside when necessary.

\section{RESULTS}

These studies were carried out on the 16 patients at different ages and at various stages of the illness. However, regardless of the stage of the disorder, the evoked response to visual stimuli recorded from the occipital region was fairly consistent. Its morphology with a given montage was the same as each 'discharge' seen in response to a single flash of light in the primary EEG trace (Figs 1 and 2). The polarity of the early components of the VER was similar to that seen in control children (Fig. 2). This response consisted of a +ve component of fairly short duration (not consistently recognizable in the control children) followed by a - ve wave of somewhat longer duration. In some of the patients an earlier short duration - ve change was seen preceding these two components.

The mean peak latency of the usual first + ve and - ve components was only slightly longer in the patient group when compared with the control group (Table). However, the amplitude of these two components in the neuronal lipidosis patients was grossly enlarged, being more than 20 times greater for the + ve component and 12 times greater for the - ve component than in the

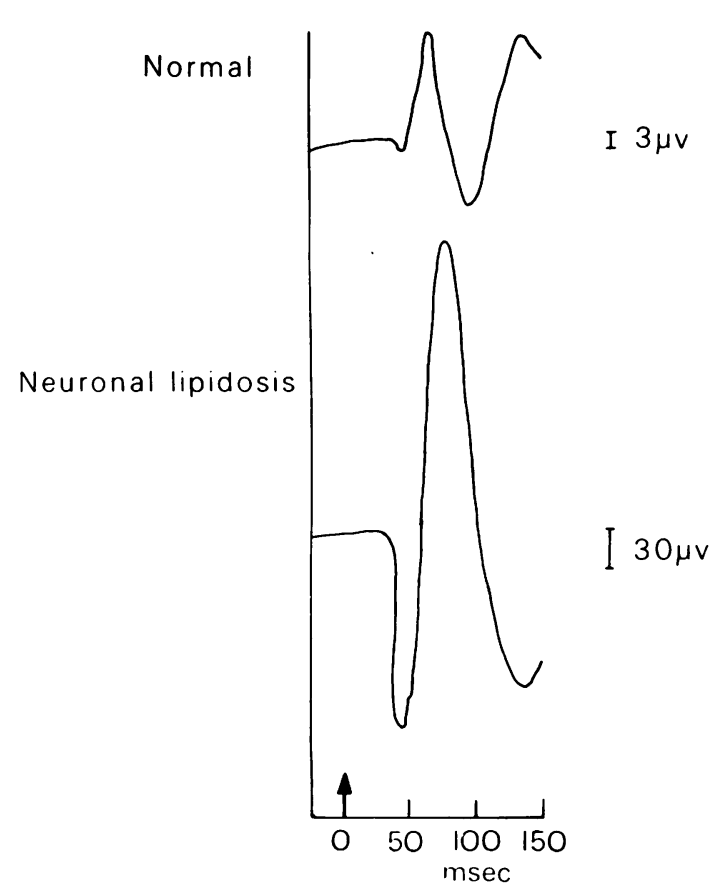

FIG. 2. The summated VERs from mid-occipital cortex from normal child and patient with 'neuronal lipidosis', both aged 6 years. Note different calibration signals. Stimulus at arrow. Negativity recorded as upward deflection.

control children (Fig. 2 and Table). While this 'averaged' response could reach an amplitude of $350-375 \mu \mathrm{V}$ (peak to peak), some of the individual responses seen on the primary EEG trace sometimes reached over $0.5 \mathrm{mV}$ in amplitude. As each child often tried to avoid looking at the lamp there was a somewhat variable amplitude of each individual response.

In one of these 16 patients VER studies were carried out at a fairly advanced stage of the disease, three months before death. At this time the characteristic discharges to low rates of photic stimulation in the primary EEG trace were no longer apparent, although they had been an obvious feature in earlier EEGs. However, VERs could still be elicited from the occipital cortex using summation techniques in this child, although the amplitude of the response was low (+ ve peak $15 \mu \mathrm{V}$, - ve peak $40 \mu \mathrm{V}$ ) but still larger than any of the control children. In 
TABLE

MEAN PEAK LATENCY AND MEAN PEAK AMPLITUDE OF VERS FROM NORMAL CHILDREN AND PATIENTS WITH 'NEURONAL LIPIDOSIS'

\begin{tabular}{|c|c|c|c|c|}
\hline & \multicolumn{4}{|c|}{ First components of visual evoked response } \\
\hline & \multicolumn{2}{|c|}{ Peak latency (msec) } & \multicolumn{2}{|c|}{ Peak amplitude $(\mu V)$} \\
\hline & $+v e$ & $-v e$ & $+v e$ & $-v e$ \\
\hline $\begin{array}{c}\text { 'Neuronal } \\
\text { lipidosis' }\end{array}$ & $50(40-60)$ & $70(55-85)$ & $155(15-375)$ & $200(40-350)$ \\
\hline $\begin{array}{l}\text { Control } \\
\text { children }\end{array}$ & $* 40(35-45)$ & $55(45-70)$ & *7 (3-10) & $15(5-25)$ \\
\hline
\end{tabular}

The range of values is shown in parentheses.

* This + ve component is recognizable in only half the controls.

addition, the frequency of stimulation appeared to be critical in this child as the cortical response was of larger amplitude and somewhat shorter latency with a flash rate of $1 / \mathrm{sec}$ rather than the more usual 2/sec used (Fig. 3). This difference was not seen either in the normal children or in the other patients who were studied at an earlier phase of the disease.

In most of our patients the ERG was not easily

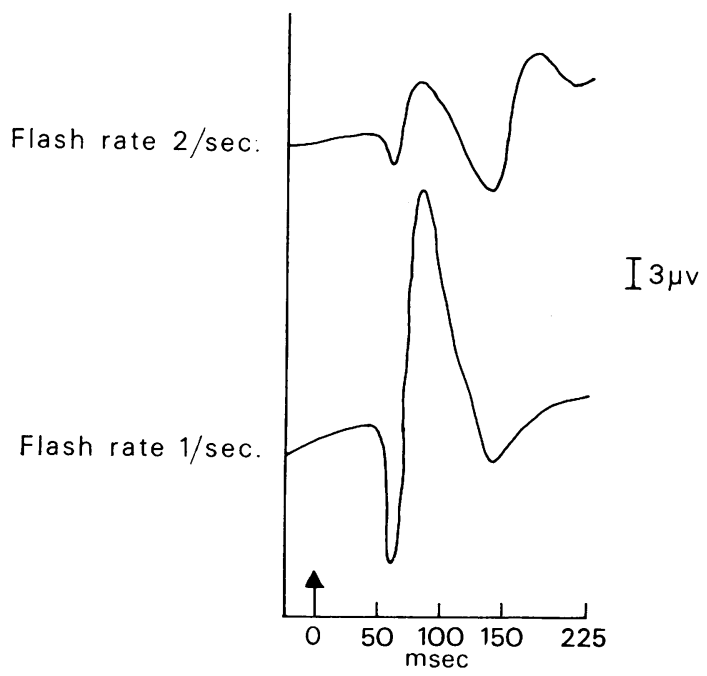

FIG. 3. Difference in amplitude of summated VERs from occipital cortex with different rates of stimuli in a patient, aged $6 \frac{1}{2}$ years, at a terminal phase of disease (see text). Stimulus at arrow. Negatinity recorded as upward deflection.

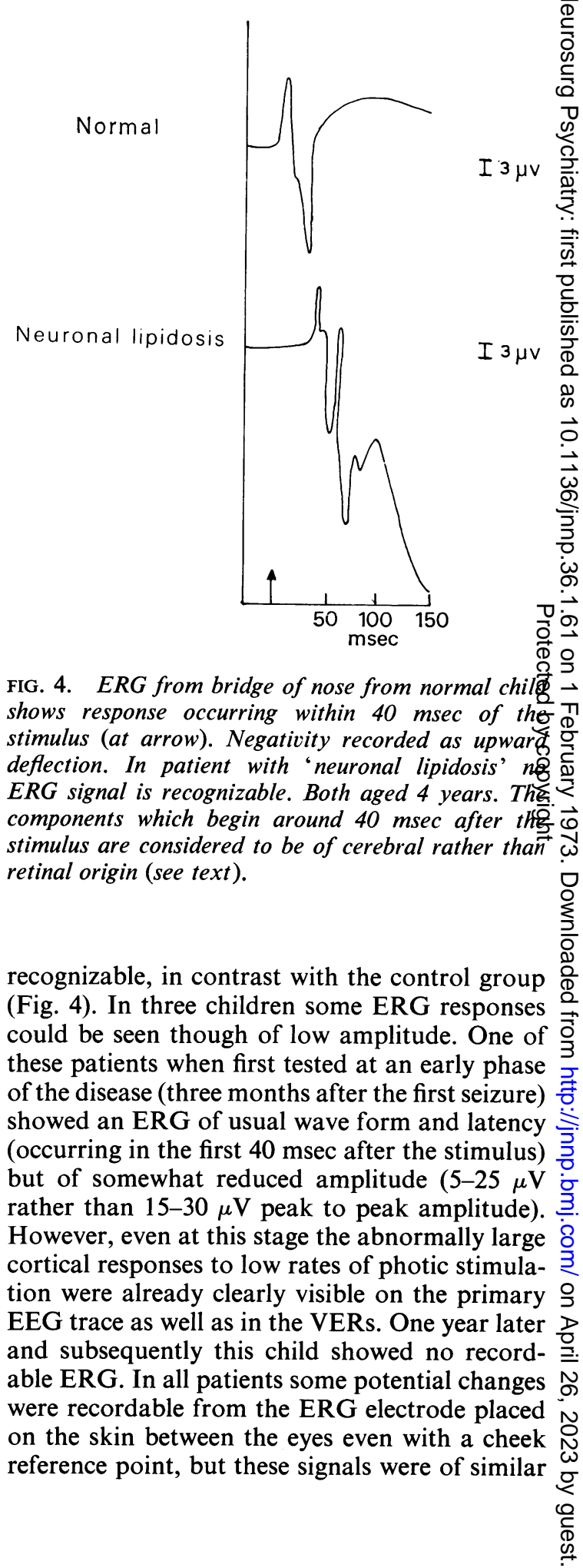


latency and wave form to the cortical evoked responses; they were therefore regarded as being of cortical rather than retinal origin. In fact, the cortical responses were usually seen over a wide area of the head, more prominent posteriorly, in the primary EEG tracing as well as with summation techniques.

Although many of the children showed very jerky movements-and often very brief generalized jerks occurred spontaneously and in relation to photic stimulation - the presence or absence of this motor phenomenon at the time of the test did not appear to alter the size or the distribution of the evoked cortical response.

\section{DISCUSSION}

An absent or markedly depressed ERG has been reported in "late infantile amaurotic familial idiocy' by Copenhaver and Goodman (1960) in marked contrast with the preservation of the ERG in Tay-Sachs disease in which only the ganglion cells rather than the rods and cones are affected. These authors considered the ERG findings to be of considerable importance in the differential diagnosis of progressive neurological disorders. The absence of an easily recordable ERG in our patients would be in keeping with the histological findings of loss of rods and cones in post mortem material (Bielchowsky, 1913; Batten and Mayou, 1915; Seitelberger, Jacob, and Schnabel, 1967) in patients with very similar clinical history to those described in the present paper. Wolter and Allen (1964) consider this loss as secondary to accumulation of 'lipid substance' in ganglion cells.

Although an absent ERG does not necessarily imply complete loss of retinal function, it is somewhat surprising that the ERG should often be affected at such a relatively early phase of the disease when clinically visual loss appears to occur rather later. This is in contrast with the early loss of vision accompanied by a decrease in the size of the ERG, found in the juvenile form of amaurotic familial idiocy (Copenhaver and Goodman, 1960). Our 16 children appeared clinically to have reasonably good vision until such a time when their general condition made such assessment impossible. In addition, any retinal pigmentary changes or optic atrophy were not usually seen until late phases of the illness.

In spite of a loss of the ERG in most of our patients, VERs were always of abnormally large amplitude and certainly did not suggest gross loss of function of the visual pathways. This combination of features would suggest preservation of macular rather than peripheral receptors, although histological reports in other cases have indicated greater loss of rods and cones at the macula (Greenfield, Aring, and Landing, 1955).

VERs were not only recordable in our patients but the first components showed similar morphology to those seen in normal children of the same age. The amplitude of these early components, however, is so grossly enlarged that each individual response is seen as a large polyphasic spike even on the primary EEG trace. The mean peak latency of these components did appear to be somewhat increased, although for some of the patients these latencies were within the normal range. An increased latency might be in keeping with slower conduction along the visual pathways, but this needs to be investigated further. Although the enlarged cortical response may be recorded from a wide area over the scalp, it is maximal posteriorly and would therefore seem to involve the usual specific visual pathways. The great increase in the amplitude of these signals presumably occurs at one or more as yet unknown sites along these pathways.

It was difficult to assess the effect of altered stimulus intensity on these abnormal evoked responses in our patients. In the primary EEG traces the discharges seen with each flash often varied in amplitude and tended to decrease when the patient tried to look away from the lamp. These individual differences were, of course, lost when the evoked responses were 'averaged'. When the lamp was held further away from the patient there was no very obvious decrease in the size of the response. No such decrease was observed in control subjects either. Presumably the stimulus remains supramaximal until much lower intensities are reached. In one of our patients stimulation was presented to each eye separately (by covering one eye at a time). In this child there was no obvious decrease in the maximum size of discharges on the primary EEG trace with monocular stimulation. The averaged 
responses did appear to be somewhat smaller though remaining abnormally large.

In normal subjects it is not usually possible to detect the response evoked by a single flash of light on the primary EEG traces without some type of superimposition or summation technique, as the size of the signal is usually much smaller than the spontaneous activity or 'noise'. In babies it is sometimes possible to record such potentials directly on the primary EEG, as during the neonatal period the response to a single flash of light is often rather large, and in addition the background activity is of relatively low amplitude (Ellingson, 1964). These responses recorded in the neonatal period have a latency of around $100 \mathrm{msec}$ and do not show any prominent short duration components.

There have been numerous reports concerning the visual evoked responses in patients with photosensitive epilepsy (Gastaut and Regis, 1964; Bergamini and Bergamasco, 1967; Broughton, Meier-Ewert, and Ebe, 1969). In some photosensitive patients an enlarged visual evoked response has been recorded, but it is usually the later components (after $80 \mathrm{msec}$ ) that are enlarged. In fact, it is the disproportionately high amplitude of the early components of the VER which is such a distinctive feature in our patients.

Enlarged VERs with the features we have described have not been seen in any other socalled 'storage disorder' affecting the brain and in particular have not been found in children suffering from the juvenile form of 'neuronal lipidosis' in whom visual symptoms and a diminution in the amplitude of the VER are an early feature (Ellingson and Schain, 1969). In a recent paper Green (1971) described a mixed group of patients suffering from 'Batten's disease' and implied that the younger patients with an enlarged VER would later show an absent VER, as seen in his older patients, as part of the evolution of this disease. In our experience, the late infantile group continues to show large responses throughout the illness, even if in one of our cases the response was relatively reduced in amplitude in a terminal phase. It is our impression that the 'late infantile' form and the 'juvenile' form of 'neuronal lipidosis' are quite distinct disease entities and do not form part of a continuum.
We have not carried out specific somatosensory evoked responses in our patients, but enlarged somatosensory responses were reported in the two siblings with this disorder described byc Carels (1960) and were also seen in some of the patients reported by Green (1971), whether or not they also showed enlarged VERs. In a heterogeneous group of progressive myoclonic disorders in different age groups, Halliday (1967) $\overrightarrow{\vec{F}}$ reported enlarged somatosensory responses as already observed in one case by Dawson (1947). It seems likely that a somatosensory response of abnormally large amplitude is not as specific as a grossly enlarged VER as seen in our patients.

The unusual combination of neurophysio- $\$$ logical findings seen in our group of children. appears to be specific for this as yet biochemically $\vec{\omega}$ unidentified metabolic disorder. It supports the diagnostic importance of the EEG findings in separating a particular disease entity from a wider group of conditions commonly referred to as 'Batten's disease'. In addition the gros? enlargement of the VERs has physiological at well as clinical interest and further studies maf lead to some understanding of the neuronat mechanisms involved.

It is a pleasure to acknowledge the help of our colleagues who referred the patients for neuro physiological investigations, in particular Dr. E. $\omega$ Brett, Dr. P. R. Evans, Dr. Rosemary Stephens, and Dr. J. Wilson. We also wish to thank Dr. Brian Lake for information about the histochemical findings, and The British Tay-Sachs Foundation for secretarial help.

\section{REFERENCES}

Batten, F. E., and Mayou, M. S. (1915). Family cerebral degeneration with macular changes. Proceedings of the Royal Society of Medicine (Section of Ophthalmology), 8, 70-90.

Bergamini, L., and Bergamasco, B. (1967). Cortical Evoked Potentials in Man. Thomas: Springfield, Ill.

Bielschowsky, M. (1913). Über spätinfantile familiäre amaurotische Idiotie mit Kleinhirnsymptomen. Deutsche Zeitschrift für Nervenheilkunde, 50, 7-29.

Broughton, R., Meier-Ewert, K.-H., and Ebe, M. (1969). Evoked visual, somato-sensory and retinal potentials in photosensitive epilepsy. Electroencephalography and Clinical Neurophysiology, 27, 373-386.

Carels, G. (1960). Étude physiopathologique d'un syndrome myoclonique chez deux enfants atteints d'une forme infantile tardive de l'idiotie amaurotique. Essai de corrélation anatomophysiopathologique. Acta Neurologica et Psychiatrica Belgica, 60, 435-464. 
Copenhaver, R. M., and Goodman, G. (1960). The electroretinogram in infantile, late infantile, and juvenile amaurotic family idiocy. Archives of Ophthalmology, 63, 559-566.

Dawson, G. D. (1947). Investigations on a patient subject to myoclonic seizures after sensory stimulation. Journal of Neurology, Neurosurgery, and Psychiatry, 10, 141-162.

Ellingson, R. J. (1964). Cerebral electrical responses to auditory and visual stimuli in the infant (human and subhuman studies). In Neurological and Electroencephalographic Correlative Studies in Infancy, pp. 78-116. Edited by P. Kellaway and I. Petersen. Grune and Stratton: New York.

Ellingson, R. J., and Schain, R. J. (1969). EEG patterns in juvenile cerebral lipidosis. Electroencephalography and Clinical Neurophysiology, 27, 191-194.

Gastaut, H., and Regis, H. (1965). Visually evoked potentials recorded transcranially in man. In Symposium on the Analysis of Central Nervous System and Cardiovascular Data Using Computer Methods. Washington, 464. Edited by L. D. Proctor and W. R. Adey. Clearing House for Federal Scientific and Technical Information: Springfield, Virginia. NASA SP-72.

Green, J. B. (1971). Neurophysiological studies in Batten's disease. Developmental Medicine and Child Neurology, 13, 477-489.

Greenfield, J. G., Aring, C. D., and Landing, B. H. (1955). Clinical pathologic conference. Case presentation. Neurology, 5, 732-739.

Halliday, A. M. (1967). The electrophysiological study of myoclonus in man. Brain, 90, 241-284.
Harden, A., and Pampiglione, G. (1970). Neurophysiological approach to disorders of vision. Lancet, 1, 805-809.

Pampiglione, G. (1956). Some anatomical considerations upon electrode placement in routine E.E.G. Proceedings Electrophysiological Technologists'Association, 7, No. 1, 20-30.

Pampiglione, G. (1961). E.E.G. in some inborn errors of metabolism. Pp. 53-63. Proceedings of the VIIth International Congress of Neurology, Rome, 1961. Vol. I. Società Grafica Romana: Rome.

Pampiglione, G. (1968). Some inborn metabolic disorders affecting cerebral electrogenesis. In Some Recent Advances in Inborn Errors of Metabolism, pp. 80-98. Edited by K. S. Holt and V. P. Coffey. Livingstone: Edinburgh.

Pampiglione, G., and Harden, A. (1973). Neurophysiological identification of a late infantile form of 'Neuronal lipidosis'. Journal of Neurology, Neurosurgery, and Psychiatry. (In press.)

Pampiglione, G., and Lehovský, M. (1968). The evolution of EEG features in Tay-Sachs' disease and amaurotic family idiocy in 24 children. In Clinical Electroencephalography of Children, pp. 287-306. Edited by P. Kellaway and I. Petersen. Almqvist and Wiksell: Stockholm.

Seitelberger, F., Jacob, H., and Schnabel, R. (1967). The myoclonic variant of cerebral lipidosis. In Inborn Disorders of Sphingolipid Metabolism, pp. 43-74. Edited by S. M. Aronson and B. W. Volk. Pergamon Press: Oxford.

Wolter, J. R., and Allen, R. J. (1964). Retinal neuropathology in late infantile amaurotic idiocy. British Journal of Ophthalmology, 48, 277-284. 